\title{
Campinas, uma vila colonial (1774-1822)
}

\author{
Paulo Eduardo Teixeira*
}

A agricultura paulista apresentou uma significativa expansão durante o final do século XVIII e início do XIX. Representativa de uma região de grandes propriedades escravistas, Campinas foi a localidade estudada devido à grande riqueza documental, de tal forma que este artigo foi pautado, principalmente, pelo Mapa Geral de Habitantes existente para o período de 1798 a 1822, acrescentando-se informações provenientes das Listas Nominativas de habitantes e dos Registros Paroquiais. Os resultados do estudo mostraram um crescimento demográfico de grande intensidade, sobretudo da população cativa.

Palavras-chave: Escravidão. Mortalidade. Nupcialidade. Natalidade. Século XVIII. Colonização.

\footnotetext{
“Universidade Estadual Paulista “Júlio de Mesquita Filho” (Unesp), Marília-SP, Brasil (ptmarilia@gmail.com).
} 


\section{Introdução}

Com sua restauração em 1765, a capitania de São Paulo passou por uma série de ações promovidas pelos governadores, que tiveram a intenção de reorganizá-la do ponto de vista político-administrativo, econômico e militar. 0 vasto território paulista, que na época abrigava também os campos de Curitiba até a foz do rio Paraná, tornou-se alvo de uma política de povoamento iniciada pelo governador Luís Antônio de Sousa Botelho Mourão, o Morgado de Mateus (BELLOTTO, 1979).

As correspondências travadas entre o governador Morgado de Mateus (1765-1775) e o futuro marquês de Pombal revelam as orientações advindas da corte para promover a formação de novas povoações, ou seja, a ereção de novas vilas, conforme destacado pelo documento a seguir:

Com grande cuidado espero as ordens que pedi a V. Ex. ${ }^{a}$ em carta de 22 de Dezembro de 1766, N.을 29 , e de 28 de janeiro de 1767, N.우 37, e ultimamente em carta de 4 de Julho do mesmo anno preterito de 1767, para effeito de me conformar com ellas em tudo o que dispozer para a fundação de novas Povoações e erecção de novas Villas, que tenho disposto nesta Capitania, das quaes necessito muito para desfazer todas as duvidas com que a cada passo me pretendem embaraçar estes estabelecimentos. ${ }^{1}$

A sujeição aos propósitos da coroa acha-se bem patenteada não apenas nessas correspondências, mas também em muitas outras que demandavam uma necessidade semelhante. Essas mesmas Instruções, especificamente as relativas à fundação de vilas, parecem dirigidas aos seus sucessores, ou ao menos foram informados sobre tais ordens, pois o governador Antonio Manoel de Mello Castro e Mendonça (1797-1802) referiu-se a elas da seguinte maneira:

Porq.' Todos os meus antecessores, fundados nas Ordens pozitivas q.' forão dirigidas a esta Cap.nia pelo Secretr. o d'Estado, q.' então era o Conde de Oeyras, em data de 22 de Julho de 1766, e outras q.' recomendão a creação de Novas Villas, com os seus competentes Postos, e Off.es da Camr. não só com effeito as crearão, mas tambem passarão a nomear os respectivos Off.es dellas. ${ }^{2}$

Assim, as declarações e ordens recebidas da metrópole portuguesa revelam um conjunto de Instruções que demonstram claramente a existência de um projeto de consolidação do domínio português na região sul do Brasil. As ordens emanadas da corte eram assimiladas pelo governador e retransmitidas às câmaras de cada vila, como consta na seguinte ordem sobre a plantação de mantimentos, podendo-se observar mais uma vez a importância dada aos aspectos relacionados à economia e ao povoamento:

Porq.to me consta a grande falta de mantimentos, q.' deixam de produzir-se nesta capitania pela ocioza liberd.e em q.' vive a mayor parte dos seus habitantes, postos

\footnotetext{
${ }_{1}^{1}$ Documentos Interessantes para a História e Costumes de São Paulo, v. 19, 1896, p. 22-23. Carta n. 22 ao Snr. Francisco Xavier de Mendonça Furtado. S. Paulo 14 de Mayo de 1768. De agora em diante será usada a abreviatura D.I.

2 D.I., v. 29, 1899, p.187-188. Para o Conselho Ultramarino dando os motivos porq.' Creou o Posto de Cap.m Mór da V. Santos na pessoa de Fran.co X.er da Costa Aguiar. S. Paulo 4 de Fevr.ํ de 1800.
} 
em vadiaçam e reduzidos a hua total pobreza, com repugnancia a todo o trabalho, sem cuidarem do seu aumento, e me ser m.to recomendado nas Reaes ordens de S. Mag.e q.'dentre os seus vassallos faça desterrar tam perniciozos vicios pondo-os náquella regularidade e sugeiçam de policia, em q.'devem viver, p.․ q.'sejão uteis a si, e ao mesmo Estado: Ordeno ao Juizes Ordinarios e Officiaes da Camera das Villas desta capitania q.'logo [...], fação produzir [...] dobrada lavoura. ${ }^{3}$

O processo não foi simples e tampouco bem-sucedido em todas as suas etapas. Não se limitou unicamente ao governo do Morgado de Mateus, pois, às vésperas de sua partida, tanto ele quanto o futuro governador, Martim Lopes Lobo de Saldanha (1775-1782), haviam recebido instruções do secretário de Estado para que os corpos de Auxiliares "não deveriam ser constituídos apenas por pessoas de posses e sim por aqueles que na paz cultivavam os solos, criavam gado e enriqueciam a terra com seu trabalho e na guerra com armas na mão defendiam das invasões inimigas seus bens, casas e famílias" (LEONZO, 1977, p. 223). As famílias e seus domicílios, muitos deles compostos também por escravos, emergiram como elementos de defesa territorial, pois sem eles seria impossível a existência de uma população estável e necessária ao estabelecimento de vilas, que, por sua vez, ofereceram o contingente de recrutas para as tropas de soldados e mão de obra para a "lavoura dobrada".

\section{A fonte: “Mappa Geral dos Habitantes”}

Para denotar a importância do “Mappa Geral dos Habitantes” enquanto fonte documental na perspectiva indicada por Henry (1976, p. 72), ou seja, de balizar todo dado numérico sob um severo exame crítico, particularmente para os períodos mais remotos, com a finalidade de utilizá-lo da melhor forma possível, foram selecionados quatro anos da vila de São Carlos ${ }^{4}$ para servirem de estudo: 1798, 1806, 1814 e 1822.

A escolha destes anos deve-se ao contexto histórico no qual ocorreu a fundação da futura cidade de Campinas, localizada no chamado oeste paulista, a cerca de $100 \mathrm{~km}$ da capital, conforme relatado no livro Tombo da Igreja de Nossa Senhora da Conceição de Campinas:

São esses os documentos relativos a creação da freguesia de N. S. da Conceição das Campinas, paragem do bairro do Matto Grosso (ou sertão) da villa de Jundiahy.

O logar devia ter começado a povoar-se de 1739 em diante, segundo as melhores versões, pois Barreto Leme veio para Jundiahy em 1730.

\footnotetext{
${ }^{3}$ D.I., v. 33, 1901, p. 57-58. “Ordem-circular às Cameras sobre a plantação de mantimentos” expedida por D. Luiz Antonio de Souza em 29 de abril de 1772.

4 Durante suas várias fases, o povoamento que veio dar origem à cidade de Campinas teve outros nomes. No período que foi um bairro rural da vila de Jundiaí era chamado de "Mato Grosso", depois, quando foi elevado à condição de freguesia (1774-1797), recebeu o nome de "Nossa Senhora da Conceição das Campinas" e, posteriormente, tornou-se a vila de São Carlos (1797-1842). Durante todo esse processo de formação espacial da vila de Campinas, notamos que não houve nenhum desmembramento de seu território, sendo o primeiro ocorrido apenas em 1924, quando Americana veio a se constituir município (FERNANDES, 2016, p. 32). Assim, a escolha dos quatro anos que serviram de estudo foi devido ao espaço de tempo entre cada um dos Mapas, de oito anos, e por representarem o período colonial da vila.
} 
O documento mais antigo a respeito da estrada do Goyas, a cuja teria se levantou nossa terra é uma relação da viagem ou bandeira do 2.ำ Anhanguéra, Bartholomeu Bueno da Silva, que partiu de S. Paulo a 3 de junho de 1722 em (sic.) das minas que seu pae, o Anhanguera $1^{\circ}$, de igual nome havia descoberto.

Sabe-se, por essa relação, que os bandeirantes levaram quatro dias para atravessar a mata espessa existente entre as villas de Jundiahy e Mogy-Guassú (não havia ainda Mogy-mirim). A espessura da matta era indicio da fertilidade da terra. Dahi, a vinda de Barreto Leme e o chamado do Frei Antonio de Padua a seus parentes. ${ }^{5}$

Por meio deste relato, notamos que, antes da restauração da capitania de São Paulo em 1765, o caminho para as minas de Goiás já era conhecido, cujo trajeto feito por meio da mata saía da cidade de São Paulo, indo em direção ao oeste, passando pela vila de Jundiaí e seguindo o caminho que era permeado por inúmeros pousos (BACELLAR, 2016), dos quais um deles ficava no bairro do Mato Grosso e que posteriormente deu origem a Campinas. Nota-se ainda que no documento foi destacado o nome de Francisco Barreto Leme, como sendo um dos moradores antigos da região, visto ser ele nomeado pelo Morgado de Mateus como "diretor" do novo povoamento de Campinas, o qual em 1779 assinou a lista nomi-

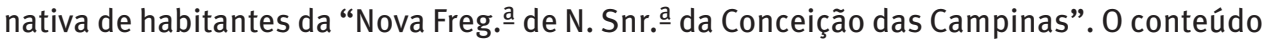
dessa lista indicou cada domicílio, ou fogo, como era denominado, assim como cada pessoa que pertencia ao mesmo, com a idade e estado conjugal, inclusive com informações sobre os escravos, apresentando, ao final, um resumo com o número total de habitantes, de fogos, assim como das pessoas que nasceram e das que morreram naquele ano e o total de habitantes divididos por faixas de idade de 15, 20 e 30 anos. Vale dizer ainda que, por

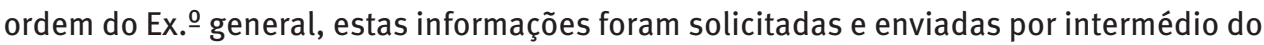
capitão-mor da vila de Jundiaí e, posteriormente, colhidas e remetidas ao fim de cada ano, como foi observado nos documentos.

Para atingir a finalidade deste estudo, ou seja, entender as dinâmicas demográficas e os movimentos de uma população que viveu em uma região de fronteira na qual foram estabelecidas grandes propriedades açucareiras com o uso do trabalho escravo, o foco das análises recaiu sobre a Campinas do período colonial, isto é, até o ano de 1822, quando então foi proclamada a independência política do Brasil. Cabe notar que, mesmo após esse marco político, a prática da coleta de dados estatísticos continuou e, no caso campineiro, isto ocorreu até 1836 , quando então não tivemos mais notícias desse tipo de documentação. Em 6 de fevereiro de 1827, em ofício enviado da vila de São Carlos, o sargento-mor Antonio Andrade explicou ao "Exm.ํㅗ. Visconde de Congonhas do Campo", que foi o primeiro presidente da Província de São Paulo, a razão de o "quadro Statistico desta Capitania” não estar pronto: "a cauza da demora foi a omissam do Vigario desta

\footnotetext{
${ }^{5}$ Livro Tombo, n. 1, da Igreja de Nossa Senhora da Conceição de Campinas, p. 9v (Arquivo da Cúria Metropolitana de Campinas).
} 
Vila, [...]; omissão que eu não pude remediar por ser de um individuo que estava fora da pequena orbita de minha autoridade". ${ }^{6}$

Assim, o "quadro Statistico" referido pelo sargento-mor remete ao resumo dos nascimentos, casamentos e óbitos da vila que eram de responsabilidade do vigário, ou seja, do poder eclesiástico. Nesse sentido, Maria Stella Ferreira Levy $(2009$, p. 158, 162) afirmou que o direito de padroado foi uma forma típica de compromisso entre a Igreja de Roma e o governo de Portugal, e pelo qual não apenas os reis portugueses, mas também os imperadores do Brasil, exerceram o governo político e religioso, visto que esse compromisso foi mantido mesmo após a independência do Brasil.

Portanto, do exemplo citado, nota-se que a autoridade civil era responsável pela confecção do Mapa Geral de Habitantes, um resumo dos dados vitais da população obtido a partir dos registros paroquiais de batismos, casamentos e óbitos, os quais retratavam o trabalho do vigário em zelar por essas informações e repassá-las ao encarregado do Mapa Geral quando da preparação do mesmo. No entanto, a esfera de autonomia da autoridade de um capitão-mor ou sargento-mor não era superior à de um vigário, os quais deveriam respeitar a autoridade religiosa.

De modo semelhante o capitão Raymundo Alvares dos Santos Prado, ao findar o "Mapa geral da nova Vila de Sam Carlos” em 1797 fez a seguinte observação:

Foi demorada a remessa desta Lista geral por dois motivos, sendo o primeiro [...] pela primeira estar errada, e sem forma alguma; e o segundo por não haver avisados para se fazer a Conta dos Nascidos, e Mortos, pela ausência do Rv. ${ }^{\circ}$ Vig.ro․?

Assim, é possível notar que, a partir de 1797, houve mudanças nas informações dos mapas de nascimentos anuais, que incluíram, na condição social de livres e cativos, a separação entre "brancos", "pretos" e "mulatos", ${ }^{8}$ a distribuição por sexo e o número de nascidos "vivos", "mortos" e "gêmeos". 0 mesmo tipo de estrutura foi aplicado aos "mapas de mortes", incluindo a distribuição dos óbitos por faixas de idade (0-1, 1-5 e 5-10 anos), o que possibilitou identificar as crianças com menos de dez anos, ao passo que os jovens e adultos com mais de dez anos foram contados em faixas decenais até 100 anos. Finalmente, de modo mais simplificado, o mapa de casamentos indicou o total de uniões por cor e condição social, sendo que aqueles referentes a 1806, 1814 e 1822 apresentavam essas informações segundo sexo dos nubentes e faixas etárias decenais a partir dos dez anos de idade.

Para que o leitor possa ter uma pequena ideia do formato do documento, a Figura 1 mostra a primeira página do Mapa Geral dos Habitantes de Campinas referente ao ano da independência política do Brasil, em 1822.

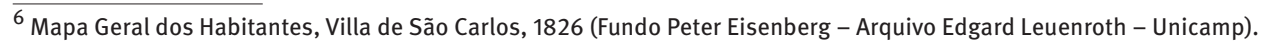

${ }^{7}$ Mapa Geral da nova Vila de Sam Carlos, 1797 (Fundo Peter Eisenberg - Arquivo Edgard Leuenroth - Unicamp).

${ }^{8} 0$ termo “mulato" aparece nos Mapas Gerais de Habitantes de forma concomitante ao termo "pardo" para indicar o sujeito que não era nem branco e nem preto, podendo ser entendidos como sinônimos.
} 
FIGURA 1

Primeira página do “Mappa Geral dos Habitantes existentes na Villa de São Carlos do anno de 1822”

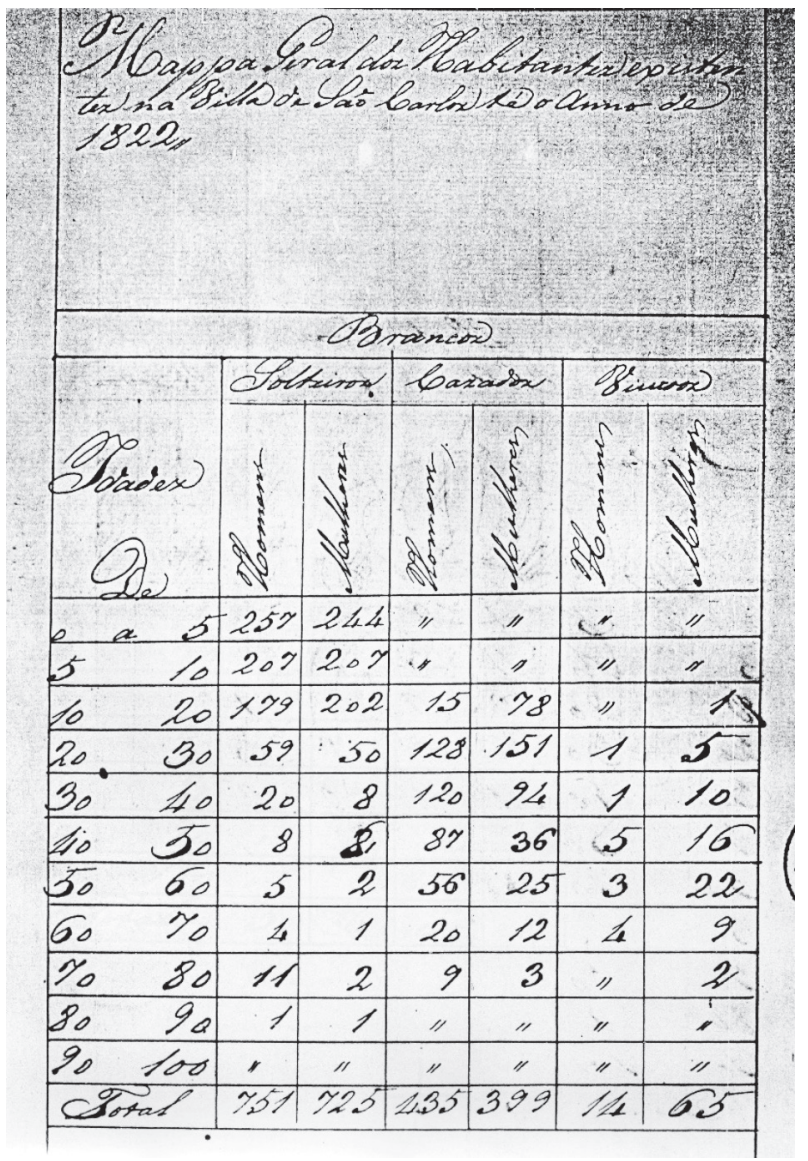

Fonte: Mapa Geral dos Habitantes de Campinas (Fundo Peter Eisenberg - Arquivo Edgard Leuenroth - Unicamp).

Observa-se, na Figura 1, que a primeira coluna indica a faixa etária das pessoas arroladas na contagem, de modo que notamos grupos etários quinquenais que informam o número de crianças de 0 a 5 anos e de 5 até 10 anos de idade, sendo os habitantes acima de dez anos contados em faixas decenais de idade, dispostos pelo estado conjugal (solteiros, casados e viúvos) e distribuídos por sexo (homens e mulheres) e pela cor/condição social (brancos, pretos livres, pretos cativos, pardos livres e pardos cativos), num total de cinco quadros, finalizando com um resumo da população pela cor e o total, que no ano em foco foi de 7.372 pessoas. Na sequência do Mapa Geral de Habitantes, encontramos os mapas dos nascimentos, óbitos e casamentos, já descritos anteriormente. Assim, segundo esses apontamentos, em 1822, houve o nascimento de 567 crianças brancas, 288 pretas e 705 pardas, morreram 237 pessoas entre adultos e crianças e foram realizados 335 casamentos. Ao final do Mapa Geral seguia um quadro de ocupações. 
Vale ainda destacar que esse tipo de "quadro Statistico" foi construído no momento descrito como período proto-estatístico (MARCílIO, 2000) e, portanto, com algumas limitações bastante visíveis em relação ao tratamento das informações, sobretudo no que diz respeito à soma de algumas variáveis. Além disso, outros pesquisadores já alertaram (NOZOE; COSTA, 1991, 1992) para o alto percentual encontrado para as idades que terminam em 0 , ou a preferência pelos números pares.

\section{Campinas, uma vila Colonial}

Em 1767 o bairro do "Matto Grosso" da vila de Jundiaí contava com 53 domicílios indicados na lista nominativa de habitantes, com uma população de 268 pessoas. Posteriormente, em 1774, foi criada a Freguesia de Nossa Senhora da Conceição das Campinas, a qual, pouco mais de 20 anos depois, tornou-se vila de São Carlos, por meio de uma determinação do então recém-empossado governador, Manuel de Melo Castro e Mendonça, em 1797.

A povoação passou, então, a ser conhecida como São Carlos, cuja atribuição, de acordo com D’Alincourt (1976, p. 51, 53), foi em "comemoração do Augusto Nome da Rainha, a Senhora D. Carlota Joaquina". No entanto, esse autor referiu-se à vila como "S. Carlos de Campinas" e, em diversas menções, abandonou o nome do santo. Apesar disso, a restauração do nome de Campinas veio apenas em 1842, por ocasião da elevação à condição de cidade. No presente artigo, doravante, será utilizado apenas o nome pelo qual ficou mais conhecida, ou seja, Campinas.

O impulso que a lavoura de cana-de-açúcar provocou na capitania de São Paulo foi muito bem estudado no clássico livro de Maria Thereza S. Petrone (1968), em que a autora remonta ao ano de 1765, ou seja, a partir da administração do governador Luís Antônio Botelho de Sousa Mourão, o Morgado de Mateus (1765-1775), como sendo o momento de expansão dessa cultura que provocou a transformação de diversas vilas paulistas, especialmente aquelas situadas na região do chamado "quadrilátero do açúcar”, demarcado pelas fronteiras de Jundiaí, Mogi Guaçu, Piracicaba e Sorocaba, na qual podemos incluir Itu, Campinas, Porto Feliz, Limeira e Rio Claro.

Outra consequência desse processo foi o grande número de concessões de sesmarias, que para Campinas ocorreu, sobretudo, no final da década de 1790, segundo Nelson Nozoe (2016, p. 35), mesmo momento que a freguesia passou à condição de vila e que a produção de açúcar atingia 16 mil arrobas a partir de 37 engenhos existentes.

As taxas de crescimento da população, como podemos observar na Tabela 1, ajudam a entender o comportamento dessa população que foi dividida entre livres e cativos. Em relação aos primeiros, notamos que há um processo de crescimento significativo até a primeira década do século XIX, certamente devido à abundância de terras para a cultura das grandes lavouras de açúcar e outros cereais, como milho, feijão, arroz e trigo. Contribuem nesse processo pessoas oriundas, principalmente, de localidades vizinhas, fato que pode ser atestado quando compulsamos a origem dos chefes de domicílio por 
intermédio das listas nominativas de habitantes. Em Campinas, 83\% dos chefes de família originaram-se da própria capitania e menos de $10 \%$ tinham nascido na vila, segundo a lista de habitantes de 1814 (TEIXEIRA, 2004). Atesta esse fato o vigário Joaquim José Gomes, por volta de 1798, quando, por ocasião do pedido ao governador para a criação da vila, alegou que "a freguesia era habitada por 2.107 pessoas, das quais 688 haviam chegado nos três últimos anos, fato indicativo da forte atração exercida pela produção açucareira" (NOZOE, 2016, p. 30).

TABELA 1

Taxa geométrica anual média de crescimento da população (1), por condição social Campinas - 1767-1829

\begin{tabular}{|c|c|c|c|c|c|c|c|}
\hline \multirow{2}{*}{ Anos } & \multirow{2}{*}{$\begin{array}{c}\text { Período } \\
n\end{array}$} & \multicolumn{2}{|c|}{ Livres } & \multicolumn{2}{|c|}{ Cativos } & \multicolumn{2}{|c|}{ Total } \\
\hline & & $N$ & $r(\%)$ & $N$ & $r(\%)$ & $N$ & $r(\%)$ \\
\hline 1767 & - & 268 & - & - & - & 268 & - \\
\hline 1774 & 7 & 388 & 5,43 & 87 & - & 475 & 8,52 \\
\hline 1782 & 8 & 456 & 2,04 & 112 & 3,21 & 568 & 2,26 \\
\hline 1790 & 8 & 921 & 9,18 & 220 & 8,81 & 1.141 & 9,11 \\
\hline 1798 & 8 & 1.807 & 8,79 & 701 & 15,59 & 2.508 & 10,35 \\
\hline 1806 & 8 & 3.365 & 8,08 & 1.392 & 8,95 & 4.757 & 8,33 \\
\hline 1814 & 8 & 3.671 & 1,09 & 2.503 & 7,61 & 6.174 & 3,31 \\
\hline 1822 & 8 & 3.866 & 0,65 & 3.506 & 8,01 & 7.372 & 2,24 \\
\hline 1829 & 7 & 3.746 & $-0,45$ & 4.799 & 4,59 & 8.545 & 2,13 \\
\hline
\end{tabular}

Fonte: Listas Nominativas de Habitantes de Campinas de 1767, 1774, 1782, 1790 e 1829; Mapa Geral dos Habitantes de Campinas para 1798, 1806, 1814 e 1822 (Fundo Peter Eisenberg - Arquivo Edgard Leuenroth - Unicamp).

(1) As estimativas de crescimento da população são realizadas pelo método geométrico. Em termos técnicos, para se obter a taxa de crescimento ( $\mathrm{r}$ ), subtrai-se 1 da raiz enésima do quociente entre a população final (Pt) e a população no começo do período considerado (P0), multiplicando-se o resultado por 100, sendo " $n$ " igual ao número de anos no período: $r=[(\mathrm{nV} P \mathrm{Pt} / \mathrm{P0})-1] \mathrm{x} 100$

Um segundo momento pode ser percebido pela queda brusca da taxa de crescimento da população livre, que passou de $1,09 \%$ para $0,65 \%$ entre 1814 e 1822 . 0 fato pode ser explicado por uma escassez de terras livres, ocasionando um período de estagnação do crescimento desse grupo por meio dos processos migratórios regionais que deslocaram de Atibaia/Nazaré/Bragança principalmente os agricultores de subsistência ${ }^{9}$ e, de Jundiaí e Itu, especialmente os produtores de açúcar.

0 terceiro momento mostrado pelos dados da Tabela 1 remete a uma queda no crescimento da população livre, que apresentou uma taxa negativa em 1829 (-0,45\%). Esta informação é reforçada pelo trabalho de Warren Dean (1977) que, ao estudar a vila de Rio Claro a partir de 1820, notou a presença de pessoas oriundas de Campinas. Em outras palavras, pode-se presumir que o processo de ocupação do chamado oeste paulista foi se consolidando à medida que a disponibilidade de terras foi diminuindo, sobretudo para a população livre e pobre, obrigando-a a marchar cada vez mais a oeste. Nesse sentido, corrobora nossa hipótese o fato de Francisco Vidal Luna e Herbert Klein (2005, p. 20)

\footnotetext{
9 0 conceito de subsistência neste trabalho refere-se aos produtos destinados ao autoconsumo e ao mercado local, enquanto o de exportação diz respeito aos bens direcionados para os mercados fora da respectiva vila, como ocorria com o açúcar.
} 
atestarem que o grande crescimento da agricultura em São Paulo, entre 1750 e 1850, deveu-se à grande abertura de terras virgens.

Em relação à população cativa, os dados da Tabela 1 reforçam que as elevadas taxas de crescimento foram um reflexo das condições externas que provocaram a expansão do açúcar, conforme demonstrado por Peter Eisenberg (1989). Do ponto de vista das condições internas, isso aponta para duas possibilidades: que o processo de ocupação de terras foi marcado por pessoas que já detinham bens, especialmente escravos (BACELLAR, 1997); e/ou que o intenso crescimento do número de escravos foi fruto da atividade açucareira desde o seu princípio e, portanto, teria possibilitado uma rápida acumulação de renda (MARTINS, 1996). Seja como for, a população cativa manteve fortíssima expansão entre 1790 e 1822, expressa por uma taxa de 15,59\% em 1798 e por uma taxa nada desprezível de $8,01 \%$ em 1822 , diminuindo para $4,59 \%$ apenas em 1829 . Sobre este momento, Slenes (1998, p. 17) afirmou que "Açúcar e escravidão rapidamente tornaram-se praticamente 'sinônimos' em Campinas e o crescimento da população cativa foi explosivo: em torno de $18 \%$ ao ano entre 1789 e 1801 , e 5\% ao ano entre 1801 e $1829 "$.

Segundo Luna (1998, p. 107), o aumento demográfico crescente verificado pela Tabela 1, com elevado porcentual de fogos com cativos, "em combinação com um alto número médio de escravos por fogo, resultou expressivo peso dos escravos no total da população." A desproporção no aumento das duas populações, de acordo com o mesmo autor, fez crescer a parcela de escravos na população e, em Campinas, diante dos elevados padrões de crescimento da população cativa, a variação no período estudado foi excepcional. Em 1774 , a população escrava representava $18,3 \%$ e, em 1822, quase se igualou à livre, com uma participação de $47,5 \%$ do total de habitantes.

Observando o Gráfico 1, nota-se que a população de condição social livre teve um papel fundamental no povoamento de Campinas até 1806, quando então passou a ocorrer um incremento da população cativa, que gradativamente cresceu a um ritmo mais acelerado do que aquele verificado para a livre, a ponto de suplantá-la em números absolutos em 1829. Aliás, entre 1806 e 1822, a camada livre praticamente manteve-se estável, passando de 3.365 pessoas, em 1806, para 3.671, em 1814, e chegando a 3.866 indivíduos em 1822.

Quando se passou para a análise da razão de sexo entre as populações livre e escrava (Tabela 2), notou-se um ligeiro predomínio das mulheres entre as pessoas de condição social livre, fato atestado por Marcílio $(1974,2000)$ para o conjunto da capitania, ao passo que, entre os cativos, prevaleceram os homens, e de forma mais acentuada à medida que o surto do açúcar avançava pelas terras campineiras no início do século XIX, com razão de sexo muito elevada, especialmente entre os escravos ditos pretos, ou seja, aqueles de origem africana. Esse movimento imigratório compulsório contribuiu decisivamente para o aumento da população de uma forma geral, assim como participou ativamente na implantação de grandes propriedades produtoras de açúcar e aguardente, isto é, os engenhos. 


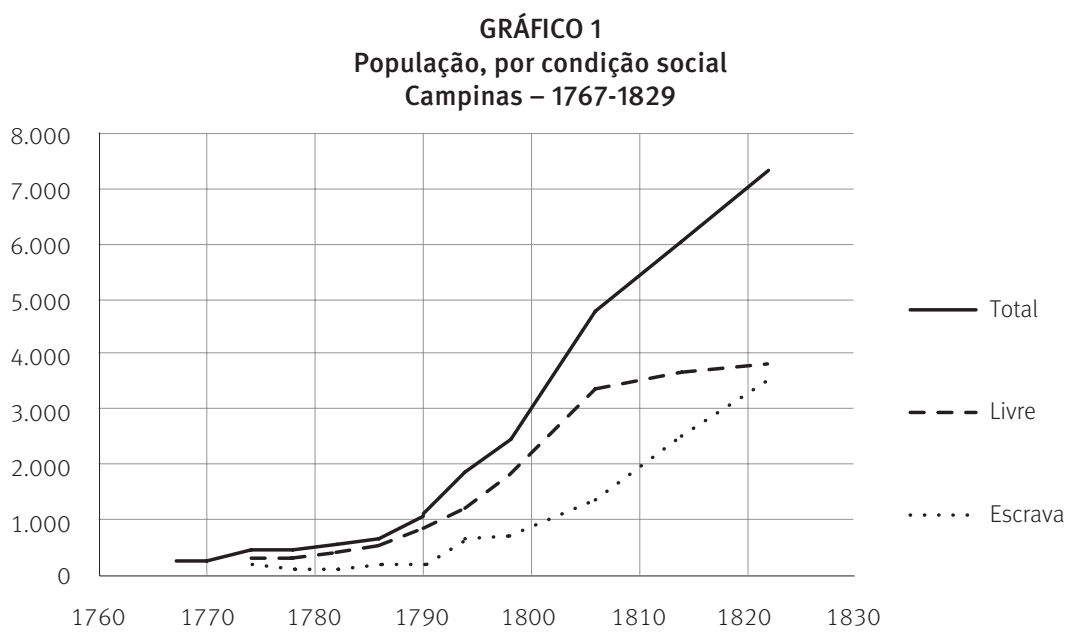

Fonte: Lista Nominativa de Habitantes de Campinas de 1767, 1770, 1774, 1778, 1782, 1786, 1790, 1794 e 1829; Mapa Geral dos Habitantes de Campinas de 1798, 1806, 1814 e 1822 (Fundo Peter Eisenberg - Arquivo Edgard Leuenroth - Unicamp).

TABELA 2

Razão de sexo (1), por condição social e cor Campinas - 1774-1822

\begin{tabular}{|c|c|c|c|c|c|c|c|c|}
\hline \multirow{2}{*}{ Anos } & \multicolumn{4}{|c|}{ Livres } & \multicolumn{3}{|c|}{ Cativos } & \multirow{2}{*}{$\begin{array}{c}\text { População } \\
\text { total }\end{array}$} \\
\hline & Brancos & Pardos & Pretos & Total & Pardos & Pretos & Total & \\
\hline $1778(2)$ & - & - & - & 99 & - & - & 100 & 99 \\
\hline 1794 (2) & - & - & - & 98 & - & - & 145 & 109 \\
\hline 1806 & 115 & 99 & 108 & 109 & 125 & 219 & 206 & 131 \\
\hline 1814 & 94 & 101 & 150 & 97 & 158 & 279 & 273 & 143 \\
\hline 1822 & 101 & 89 & 76 & 96 & 111 & 264 & 257 & 150 \\
\hline
\end{tabular}

Fonte: Mapa Geral dos Habitantes de Campinas (Fundo Peter Eisenberg - Arquivo Edgard Leuenroth - Unicamp).

(1) Número de homens por 100 mulheres.

(2) Os dados para esses anos foram obtidos pelas Listas Nominativas de Habitantes (Fundo Peter Eisenberg - Arquivo Edgard Leuenroth - Unicamp).

Estas grandes unidades produtoras baseavam seu trabalho na mão de obra masculina africana e jovem, ou seja, eram nos grupos etários de 10 a 20 e de 20 a 30 anos de idade que predominavam os maiores índices de masculinidade. Na análise dos Mapas Gerais, verificou-se que a razão de sexo entre os cativos pretos e solteiros era de 364 homens por 100 mulheres, em 1814, e 395, em 1822, valores muito acima daqueles encontrados para a população cativa total para os mesmos anos (Tabela 2). Essa análise mais detalhada revelou ainda que, em 1814, entre as crianças cativas de 0 a 5 anos, a razão de sexo era de 94, sinalizando, portanto, um relativo equilíbrio entre os nascidos debaixo do cativeiro, número muito próximo também ao encontrado para 1822. Por sua vez, a relação entre homens e mulheres com idades que variavam de 10 a 20 anos chegou a 607 em 1814 e 399 em 1822, sendo que nas faixas de idade de 20 a 30 a razão de sexo era de 387 e 1.040 , respectivamente nesses dois anos. Portanto, ficou patente a força do comércio de escravos que favoreceu o ingresso de trabalhadores jovens, entre 10 e 30 anos, demonstrando o vigor da economia açucareira na região de Campinas para importar o braço africano. 
0 reflexo direto desse processo migratório forçado de mão de obra cativa pode ser mais bem percebido no Gráfico 2, que apresenta a população por condição social e cor. Nota-se que, em 1798, havia predomínio da população livre e branca, com uma participação de mulatos e pretos livres que cresceu significativamente até 1814, quando houve uma estagnação no aumento desse segmento de pessoas livres, ao lado das brancas. Deve ser dito que o número de indivíduos identificados nos Mapas Gerais como sendo de cor preta e condição social livre é diminuto, ocorrendo apenas 14 casos em 1798, com aumento para 48 pessoas em 1806, mas reduzindo para apenas seis homens e quatro mulheres, em 1814, e vindo a ter 23 pretos livres no ano da independência do Brasil, dos quais 12 eram casados e 11 eram solteiros. Assim, pode-se inferir que até esse momento Campinas era uma região de fronteira aberta que abrigou uma população livre e mestiça, embora com poucos recursos para adquirir muitos escravos ou implantar um engenho. Em suma, a população de livres em Campinas permaneceu quase a mesma ao longo das primeiras décadas do século XIX, perdendo participação relativa no total de habitantes.

GRÁFICO 2

População, por cor e condição social

Campinas - 1798-1822

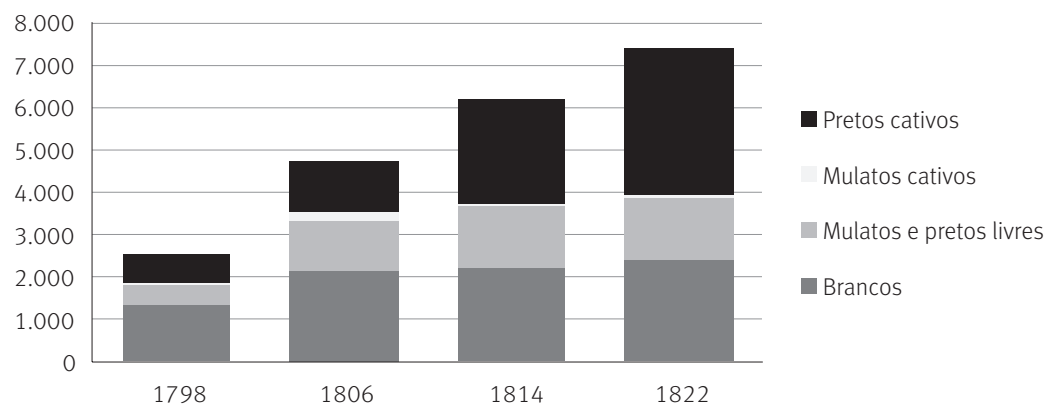

Fonte: Mapa Geral dos Habitantes de Campinas (Fundo Peter Eisenberg - Arquivo Edgard Leuenroth - Unicamp).

Em relação aos cativos, a presença de mulatos ou pardos nessa condição sempre foi bem menor do que a de africanos. Os chamados "gentios de Guiné” predominaram dentre os originários de Angola, Congo e Moçambique. Ainda havia os de Benguela e de “Nação”, uma terminologia difícil de determinar a origem e que apareceu com frequência nas listas nominativas dos habitantes de Campinas. 0 fato é que os africanos cresceram numericamente a cada ano estudado e ao fim, isto é, em 1822, eles se tornaram tão visíveis a ponto de se insurgirem contra a ordem estabelecida, uma vez que nada foi feito pelo Estado recém-inaugurado após o 7 de setembro em relação à condição daquelas pessoas que viviam debaixo do cativeiro. Por isso, vale dizer que, em meados dos anos 1830, ou seja, uma década depois, Campinas viveu uma das grandes rebeliões de escravos oriundos dessas grandes propriedades escravistas, estudada de maneira minuciosa por Ricardo Pirola (2005). 
Quando avaliamos o crescimento demográfico diferenciado pela condição social e por meio das faixas de idade, entre livres e escravos, fica patente essa distorção entre os dois segmentos, ${ }^{10}$ conforme mostram os Gráficos 3, 4 e 5.

Observando o Gráfico 3, nota-se que, em 1806, a pirâmide etária da população livre caracterizava-se por ter uma base larga, o que implica um número expressivo de crianças até dez anos de idade, com relativo equilíbrio entre todas as faixas etárias, denotando a presença de muitos casais com filhos. Isso reforça a hipótese de que, até aquele momento, a localidade era polo de atração de migrantes.

\section{GRÁFICO 3}

Estrutura da população livre, por idade e sexo

Campinas - 1806

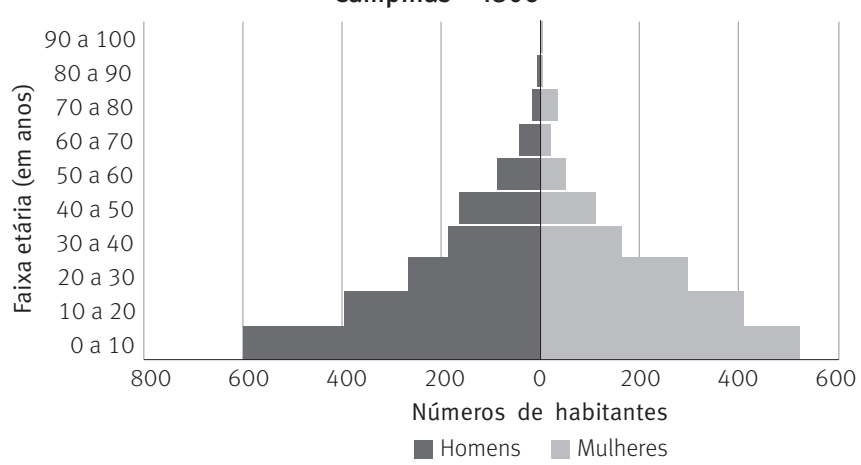

Fonte: Mapa Geral dos Habitantes de Campinas (Fundo Peter Eisenberg - Arquivo Edgard Leuenroth - Unicamp).

A observação da população livre em 1814 (Gráfico 4) revelou um outro momento no qual se percebeu uma ligeira mudança na pirâmide etária. A base larga foi mantida, com a grande presença de crianças de ambos os sexos, porém, nas faixas de 10 a 30 anos, houve uma redução do número de habitantes, mas sobretudo de homens, sinalizando um movimento migratório oscilante devido à entrada e saída de pessoas em idade adulta.

Por fim, a pirâmide etária de 1822 (Gráfico 5) indicou a persistência do processo de saída de um maior número de homens entre os 10 e 30 anos de idade, que se direcionaram rumo ao oeste paulista, atingindo outras localidades em que as terras eram abundantes. Ao consultar a lista nominativa de habitantes de Rio Claro, Warren Dean (1977, p. 22) comentou que, dos 231 domicílios existentes, quase 50\% dos chefes de família

[...] tinham nascido fora do povoado, em locais geralmente próximos e um pouco distanciados das regiões ainda inexploradas. A maioria tinha vindo de Mogi-Mirim, Bragança e Nazaré, municípios a sudeste, com uma alta proporção de pequenas propriedades em declínio. Alguns eram de Campinas e Itu, ao sul, uns poucos eram oriundos de municípios mais distantes [...].Grifo acrescido no original.

\footnotetext{
${ }^{10}$ As pirâmides etárias apresentadas nos Gráficos 3, 4 e 5, para a população livre, e 6, 7 e 8, para a população escrava, foram construídas a partir das informações dos Mapas Gerais de Habitantes de 1806, 1814 e 1822. Como eles apresentam o número de habitantes agregados em faixas etárias quinquenais para as crianças de até dez anos, e decenais para as faixas posteriores, optamos por agregar as duas primeiras faixas quinquenais e assim manter um padrão comparativo com as demais faixas de idade.
} 


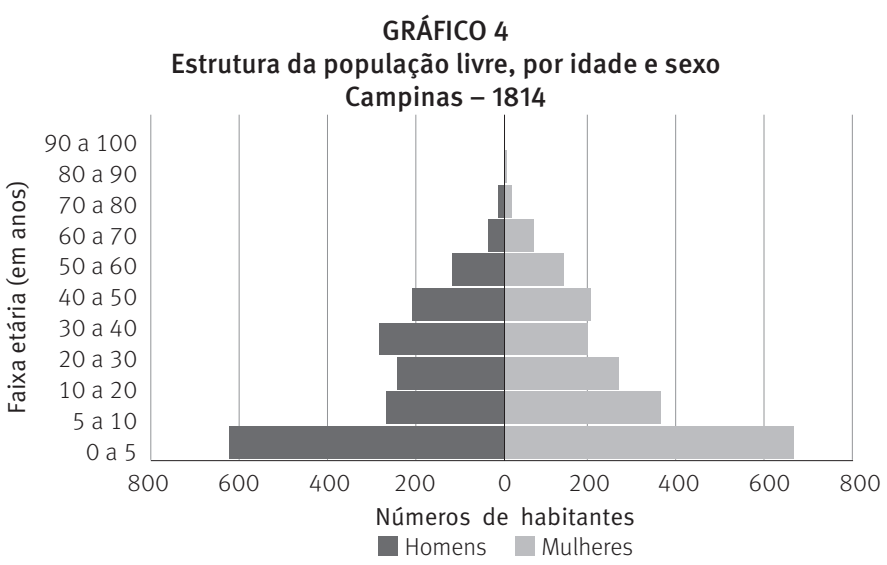

Fonte: Mapa Geral dos Habitantes de Campinas (Fundo Peter Eisenberg - Arquivo Edgard Leuenroth - Unicamp).

Em suma, esse processo foi o responsável pela formação de muitos domicílios sob a chefia feminina da casa, quando em 1829 as mulheres lideraram quase um quarto dos 950 domicílios existentes em Campinas (TEIXEIRA, 2004, p. 100).

GRÁFICO 5

Estrutura da população livre, por idade e sexo

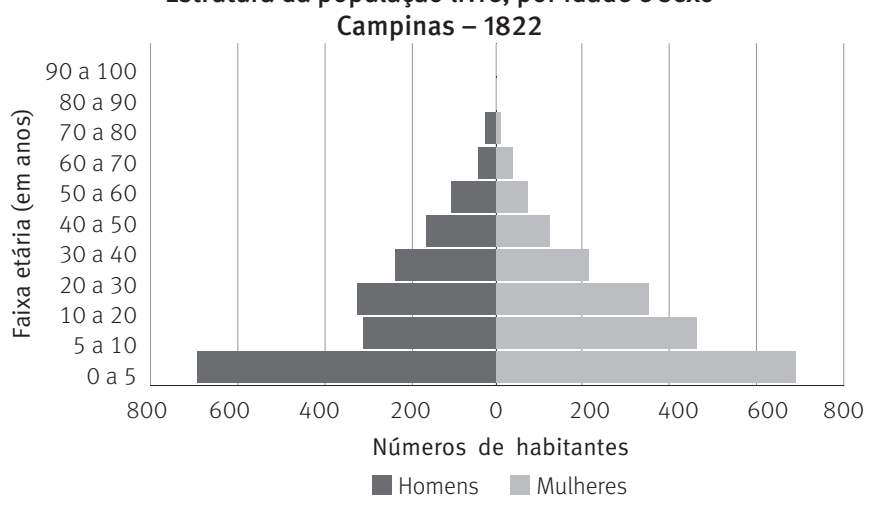

Fonte: Mapa Geral dos Habitantes de Campinas (Fundo Peter Eisenberg - Arquivo Edgard Leuenroth - Unicamp).

A presença de engenhos em Campinas também foi reveladora desse processo de valorização das terras e, ao mesmo tempo, de expulsão daqueles que não tinham condições de instalar um engenho. Segundo depoimento do viajante D’Alincourt (1976), que visitou a vila de São Carlos em 1818, havia 45 engenhos movidos pela força animal e somente 15 engenhos d'água, reiterando a necessidade de recursos para tais construções.

Já a população escrava existente em Campinas no início do século XIX estava estruturada na forma de uma pirâmide de base reduzida em relação às faixas de idade de 10 a 30 anos, com predomínio de crianças de até dez anos de idade do sexo masculino, padrão de elevada presença masculina que irá se estender pelas faixas seguintes (Gráfico 6). 


\section{GRÁFICO 6}

Estrutura da população cativa, por idade e sexo

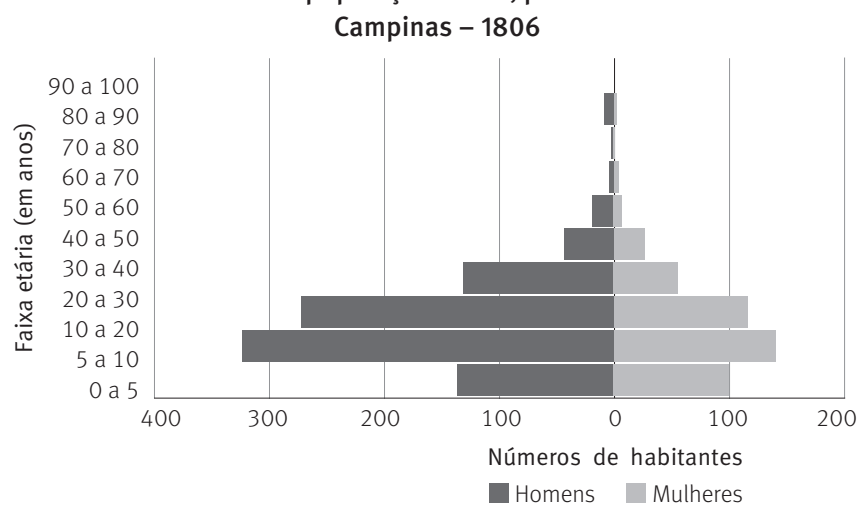

Fonte: Mapa Geral dos Habitantes de Campinas (Fundo Peter Eisenberg - Arquivo Edgard Leuenroth - Unicamp).

Para o ano 1814 (Gráfico 7) não houve grandes mudanças em relação a 1806, ou seja, seguiu a tendência já observada de um grande contingente de homens e um número bem menor de mulheres, a uma proporção média de três homens para cada mulher. Essa desproporção, como já foi apontada, recaía de maneira mais intensa sobre os jovens e adultos, elevando essa relação para quatro homens por mulher. Isso implicou a dificuldade de formação de famílias estáveis, uma vez que muitos homens estavam destinados a se manterem solteiros, enquanto a mesma situação proporcionou para as mulheres cativas a possiblidade de escolherem seus parceiros dentro de um estoque muito maior de possíveis maridos, tornando-se mais exigentes dentro desse mercado matrimonial. Essa foi a perspectiva de análise que levou Slenes (1999) a sugerir o casamento como forma de estratégia entre os senhores para controlar os seus escravos e assim tentar impedir as rebeliões em suas propriedades.

\section{GRÁFICO 7}

Estrutura da população cativa, por idade e sexo

Campinas - 1814

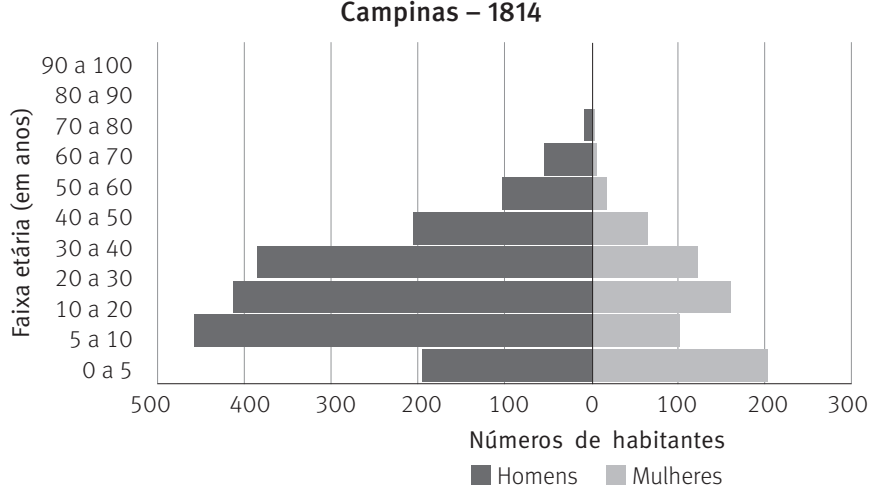

Fonte: Mapa Geral dos Habitantes de Campinas (Fundo Peter Eisenberg - Arquivo Edgard Leuenroth - Unicamp). 
O final do período colonial para os grandes proprietários de Campinas foi de crescimento dos engenhos e do número de escravos, sobretudo homens e adultos, reiterando um processo de acumulação econômica que propiciou o aumento não apenas da produção de açúcar, mas também da riqueza na forma de cativos, em sua maior parte africanos do sexo masculino (Gráfico 8). Assim, muitas pessoas que migraram para Campinas trouxeram em seu cabedal escravos para trabalharem nas terras adquiridas ou herdadas de seus familiares, como se depreende do Cadastro dos Bens Rústicos de 1818, um documento que foi produzido no final do período colonial e que retratou os proprietários de terras de Campinas, como, por exemplo, o caso do capitão Floriano de Camargo Penteado, que aparece na documentação com duas propriedades como "herança”, sendo a menor "explorada pelo filho", isto é, uma área de 1.000 braças de testada por 1.000 de fundo, cultivada pelos 30 escravos existentes na fazenda, enquanto na outra, ainda maior, com área de 1.000 braças de testada e 1.500 de fundo, trabalhavam 50 cativos. ${ }^{11}$

GRÁFICO 8

Estrutura da população cativa, por idade e sexo Campinas -1822

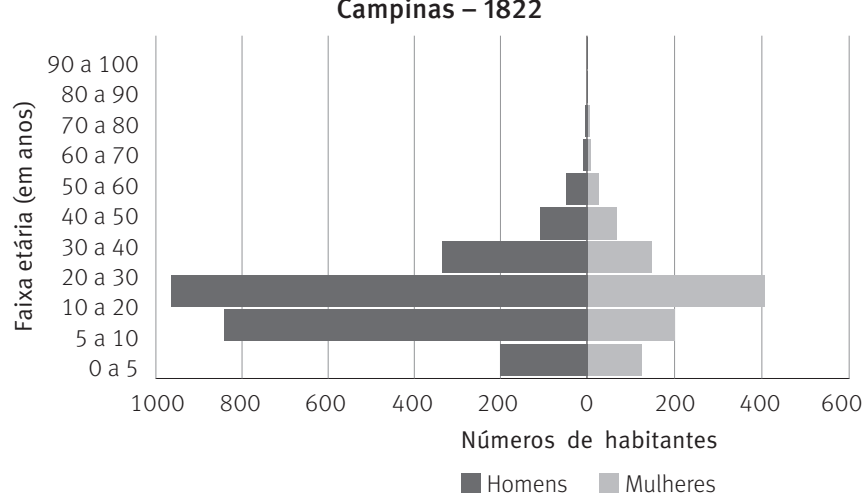

Fonte: Mapa Geral dos Habitantes de Campinas (Fundo Peter Eisenberg - Arquivo Edgard Leuenroth - Unicamp).

Por sua vez, ao se realizar uma análise demográfica dos registros históricos sobre o número de casamentos, nascimentos e mortes, foi possível avaliar os comportamentos das duas populações, livre e escrava, sob outras perspectivas. 0 Gráfico 9, que apresenta as taxas de nupcialidade de livres e cativos, revela traços que denotam a regularidade dos matrimônios entre os livres com uma perspectiva de crescimento que se manteve até 1814 , ocorrendo, a partir daí, a diminuição do número de uniões.

\footnotetext{
${ }^{11} \mathrm{~A}$ braça era uma unidade de medida de comprimento muito usada no período colonial e imperial e equivale a 2,2 metros (LEMOS BRITO, 1980, p. 352). A "testada" de um terreno corresponde à sua largura e o "fundo" ao comprimento. 0 Cadastro de Bens Rústicos de 1818 para Campinas está no Arquivo do Estado de São Paulo.
} 
GRÁFICO 9

Taxas brutas de nupcialidade (1) da população livre e cativa

Campinas - 1774-1822

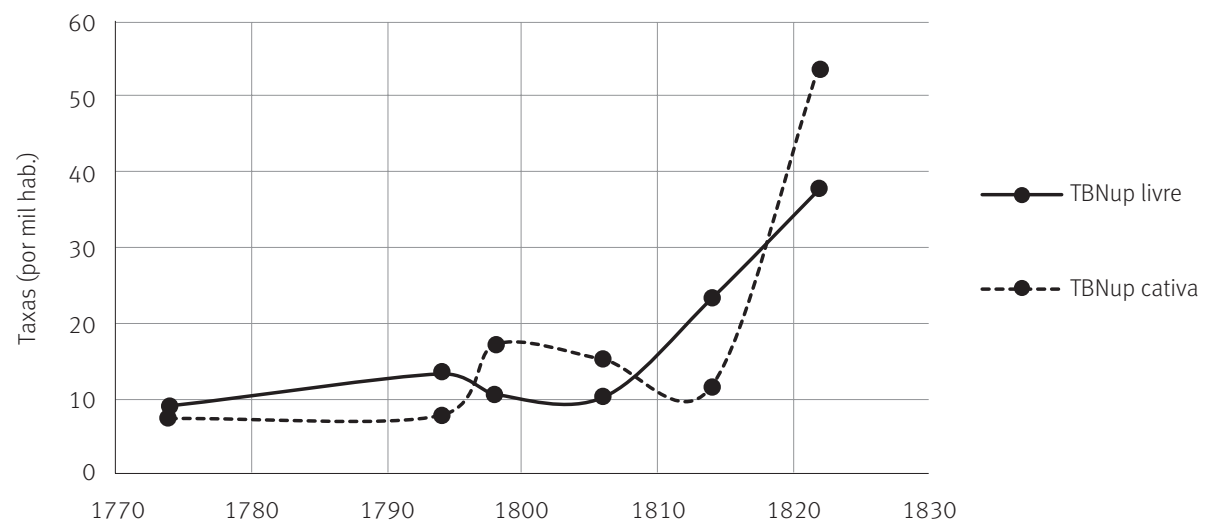

Fonte: Listas Nominativas de Habitantes; Registros Paroquiais de Casamentos; Mapa Geral dos Habitantes de Campinas (Fundo Peter Eisenberg - Arquivo Edgard Leuenroth - UNICAMP).

(1) A taxa de nupcialidade (denominada também taxa bruta de nupcialidade) é calculada pela relação entre o número de casamentos de um determinado ano e o número médio da população, multiplicado por 1.000 .

Apesar das condições materiais tão adversas daqueles que estavam sob o cativeiro em Campinas, que impuseram grande dificuldade para a existência de um maior número de casais unidos pelo matrimônio religioso, tais como a elevada razão de sexo, ainda assim notamos que houve alguns momentos em que a taxa de nupcialidade escrava atingiu $20 \%$, ou seja, correspondeu a 14 uniões para uma população de 701 indivíduos em 1798, enquanto no mesmo ano houve 19 casamentos entre a população livre de 1.807 pessoas, resultando na taxa de 10,5\%o. Em Montevidéu a taxa de nupcialidade de livres foi de 15,4\%o, em 1791, caindo para 12,9\%o, em 1810 (CABALLERO, 1987, p.306), enquanto na localidade brasileira de Curitiba, em 1803, esse índice foi de 9,9\%o (KUBO, 1974, p. 77). Por sua vez, em Franca, também uma área da fronteira paulista, em 1814 e 1820, as taxas de nupcialidade para o total da população foram de $24,6 \%$ e $23,7 \%$, respectivamente (AISSAR, 1980, p. 111), valores que se aproximam mais do contexto de Campinas. E no cômputo geral da capitania de São Paulo, as taxas de nupcialidade corresponderam a 14,9\%o, em 1803, e 8,2\%o, em 1822 (MARCÍLIO, 2000, p. 90). Assim, outras variáveis que podem ajudar a compreender os processos de crescimento populacional, como atestado por Teixeira (2011), são a idade ao casar, a duração da união e o recasamento.

Dadas as variações nos processos de coleta das informações pelos agentes locais responsáveis pela confecção dos documentos, as mesmas podem representar flutuações dos números dos registros vitais, sendo que a identificação de erros pode ser difícil para o pesquisador. Para atenuar tais problemas, o cruzamento com outras fontes documentais foi uma alternativa adotada neste estudo. Para exemplificar, apontamos no Gráfico 10 os dados comparados dos nascimentos de pessoas livres existentes nos Mapas Gerais de Habitantes com as informações dos registros paroquiais de batismo de 1803, 1814 e 1822. 0 resultado para este último ano revelou discrepância, quando foram registrados 
974 nascimentos no Mapa Geral, contra 314 batismos arrolados nos livros da Igreja de Nossa Senhora da Conceição das Campinas. Apesar de serem frequentes as diferenças de dados de um tipo de documento para outro, nunca chegaram a alarmar como neste caso, pois a taxa de natalidade da população livre variou de $82,5 \%$ o (nos registros paroquiais) para 255,9\%o (no Mapa Geral). Portanto, fica aqui essa observação para que o leitor possa entender os números apresentados com a mesma cautela com que foram produzidos. Não obstante, fica expressa a limitação implícita em várias medidas adotadas nos estudos de demografia histórica, quando somos levados a utilizar distintas fontes para a construção dos dados estatísticos, que, no caso do presente estudo, foram as listas nominativas de habitantes, os Mapas Gerais e os registros paroquiais.

GRÁFICO 10

Taxas brutas de natalidade (1) da população livre e cativa

Campinas - 1774-1822

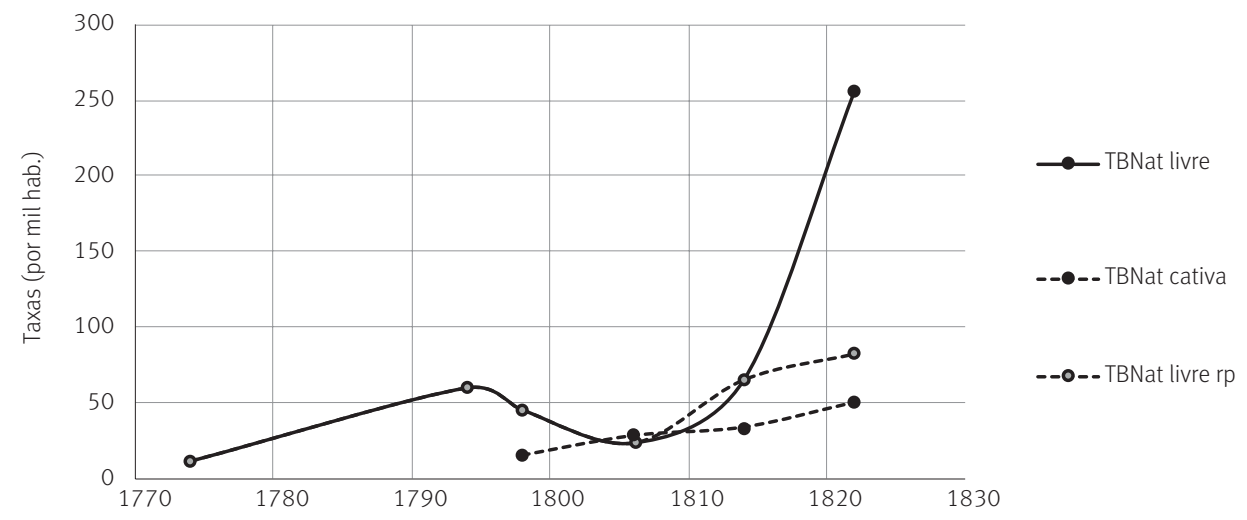

Fonte: Mapa Geral dos Habitantes de Campinas (Fundo Peter Eisenberg - Arquivo Edgard Leuenroth - Unicamp); registros paroquiais de batismos (Arquivo da Cúria Metropolitana de Campinas).

(1) 0 cálculo da taxa de natalidade (denominada também de taxa bruta de natalidade) corresponde à divisão do número de nascimentos em um determinado ano pela média da população do mesmo ano, multiplicado por 1.000. A taxa bruta de natalidade livre baseada nos registros paroquiais de batismo foi indicada pela sigla TBNat livre rp.

Ainda no Gráfico 10, nota-se o maior número de crianças nascidas vivas entre as livres, embora em 1806 as duas curvas se aproximem, indicando certa proporcionalidade dos nascimentos em relação à população total de cada segmento. Elevados índices também foram encontrados por Maria Luiza Marcílio (1986) ao estudar Ubatuba, onde a taxa de natalidade atingiu 43\%o em 1798 e chegou a 47,6\%o em 1818, números que se aproximam daquele observado por Elvira Kubo (1974) para Curitiba em 1803 (47,4\%o). Ao estudar o crescimento da população em Franca durante a primeira metade do século XIX, Aparecida da Glória Aissar (1980) anotou taxas de natalidade da população livre e escrava que atingiram a marca de $29,5 \%$ om $1806,111,6 \%$ om 1814 e $85,1 \%$ em 1820 . Tais resultados, também expressos para a situação da capitania como um todo, refletem, para Marcílio (2000, p. 91) ou taxas de nupcialidade muito altas, "com idade média ao casar da mulher muito precoce e insignificantes proporções de celibato feminino definitivo; ou os niveis de nascimentos ilegítimos da região", sendo possível a conjugação de ambos os fatores. 
Estes elevados índices de natalidade expressam as condições socioeconômicas do período e as diferenças entre livres e escravos, mas devem também nos alertar para o método de cálculo da taxa bruta de natalidade ou taxa anual média de natalidade, como também é chamada, que, ao usar como denominador comum o número da população total, deixa de expressar exclusivamente o indicador da população que tem papel preponderante em todas as etapas do processo reprodutivo e que efetivamente se encontra exposta ao risco de procriação, que são as mulheres em idades férteis, ou seja, em idades que variam de 15 a 50 anos (WELTI, 1997). De qualquer forma, as taxas de natalidade permitem certo grau de comparação com as taxas de mortalidade e de crescimento da população, uma vez que cada uma delas utiliza o mesmo denominador.

Ao se fazer uma análise comparativa entre as informações de óbitos contidas nos registros paroquiais e nos Mapas Gerais, notamos que as taxas extraídas desses dois documentos diferem, conforme pode ser visto na Tabela 3.

TABELA 3

Taxas brutas de mortalidade, por tipo de documento Campinas - 1798-1822

\begin{tabular}{|c|c|c|c|c|c|}
\hline \multirow{2}{*}{ Anos } & \multirow{2}{*}{ População total } & \multicolumn{2}{|c|}{ Mapas Gerais } & \multicolumn{2}{|c|}{ Registros paroquiais } \\
\hline & & Óbitos & TBM (\%o) & Óbitos & TBM (\%o) \\
\hline 1798 & 2.508 & 93 & 37,1 & 90 & 35,9 \\
\hline 1806 & 4.757 & 268 & 56,3 & 232 & 48,8 \\
\hline 1814 & 6.176 & 241 & 39,0 & 198 & 32,1 \\
\hline 1822 & 7.372 & 247 & 33,5 & - & - \\
\hline
\end{tabular}

Fonte: Mapa Geral de Mortes de Campinas (Fundo Peter Eisenberg - Arquivo Edgard Leuenroth - Unicamp); registros paroquiais de óbitos (Arquivo da Cúria Metropolitana de Campinas).

Pela comparação das taxas de mortalidade para cada ano, notamos vários comportamentos, como de similitude das informações para o ano de 1798, ou de discrepâncias geradas por subtração ou soma de casos de mortes, como em 1806 e 1814, que geraram variações significativas nos cálculos dessas taxas, sobretudo por estarmos tratando de populações relativamente diminutas e impactadas também pela possibilidade de mobilidade espacial e, principalmente, pela força da morbidade causada pelas enfermidades infecciosas e parasitárias. Por fim, em virtude da perda do livro de registro de óbitos que abrange o período 1819-1831, contamos apenas com a informação do Mapa Geral de 1822, que permitiu o cálculo da referida taxa bruta de mortalidade.

Nota-se, ainda, que os registros de óbitos indicados pela Igreja nunca foram iguais aos números arrolados nos Mapas Gerais, o que gerou taxas de mortalidade sempre mais baixas quando compulsamos os registros paroquiais, o que alerta para o fato já mencionado de que distintas fontes podem afetar os resultados e induzir a erros de estimativas. Assim, como decorrência desse exercício, pudemos apontar algumas das fragilidades dessas fontes, assim como seus potenciais, pois ao menos indicam uma tendência geral dos números que permitem, ainda que com as ressalvas de quem pesquisa com base em dados de um período proto-estatístico, evidenciar ou sinalizar os caminhos da demografia histórica. 
Assim, o Gráfico 11 é parte desse exercício de calcular as taxas de mortalidade da população livre e escrava distribuídas por seis pontos, nos quais os dois primeiros correspondem aos anos de 1774 e 1794, cujos dados foram obtidos por meio dos registros paroquiais de óbitos e das listas nominativas de habitantes, seguidos dos anos que obtivemos informações dos Mapas Gerais de mortes (1798, 1806, 1814 e 1822).

\section{GRÁFICO 11}

Taxas brutas de mortalidade (1) da população livre e cativa

Campinas - 1774-1822

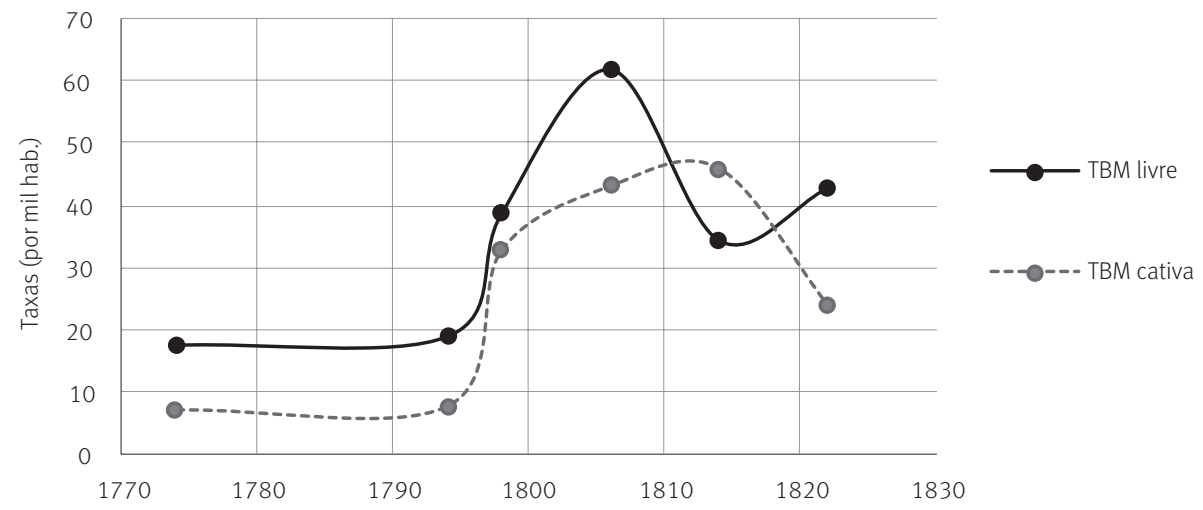

Fonte: Mapa Geral dos Habitantes de Campinas (Fundo Peter Eisenberg - Arquivo Edgard Leuenroth - Unicamp); registros paroquiais de óbitos (Arquivo da Cúria Metropolitana de Campinas); Listas Nominativas de Habitantes.

(1) A taxa de mortalidade (denominada também de taxa bruta de mortalidade) é calculada pela relação entre o número total de óbitos em um dado ano pela média da população do ano, multiplicado por 1.000 habitantes.

0 resultado para a população livre de Campinas foi de mortalidade mais elevada do que a dos escravos na maior parte do período, o que pode estar relacionado ao sub-registro dos óbitos de cativos por parte de seus senhores, ou até mesmo a um maior cuidado dos senhores em relação aos seus pecúlios, uma vez que, como cristãos, deveriam cuidar de seus escravos ao mesmo tempo que isso era conveniente, já que poderiam experimentar menores perdas (ABREU, 2007, p. 769). De todo modo, a taxa bruta de mortalidade de livres passou de $16,8 \%$ em 1794 para $38,7 \%$ em 1798 , atingiu a elevadíssima marca de 61,8\%o, em 1806, retornou aos níveis de 34,3\%o, em 1814, e chegou a 42,2\%o, em 1822.

Para termos um parâmetro de comparação, a taxa bruta de mortalidade da população livre em Curitiba foi de 16,3\%o, em 1803 (KUBO, 1974, p.77) e, em Franca, a taxa de mortalidade da população livre e escrava correspondia a 19,7\%o, em 1814, aumentando para 34\%o, em 1820 (AISSAR, 1980, p. 123). Esses números sugerem que as altas taxas de mortalidade de Campinas não eram as únicas da capitania durante o período estudado, pois, ao avaliar as estatísticas dos óbitos para o seu conjunto, Marcílio (2000, p. 89) afirmou que "foram encontradas taxas de mortalidade inferiores a dezessete por mil, inconcebíveis para a época e para a situação geral da população e da sociedade”. A razão disso, segundo a autora, foi o "pronunciado sub-registro", que, apesar de acentuado, por meio de controle dos resultados apresentados pelos mapas da população livre, encontrou taxas de $23 \%$, 
para 1798 , e $27,7 \%$, para 1818 , enquanto entre a população feminina nesses mesmos anos foram estimadas taxas de $42 \%$ o (MARCÍlIO, 2000, p. 89, 90).

Esses apontamentos alertam, em primeiro lugar, para a diferença entre as taxas de mortalidade masculina e feminina; em segundo, para as diferenças das taxas encontradas entre distintas faixas de idade (embora não tenha sido este o objetivo do presente estudo), sendo que o efeito da idade implica a nítida diferença dos resultados do cálculo da taxa de mortalidade quer infantil, quer de jovens ou ainda de pessoas com mais de 50 anos; e, em terceiro, para as condições de vida e sanitárias de uma dada população, conforme procuramos demonstrar em relação à comparação entre as taxas de livres e escravos.

Finalmente, ao examinar o conjunto das taxas de nupcialidade, natalidade e mortalidade da população livre (Gráfico 12), nota-se que, apesar das altas taxas de mortalidade, os nascimentos foram importantes para determinar um crescimento vegetativo dessa população. Os casamentos ocorridos na própria paróquia e a presença de muitos casais advindos de um processo migratório interno e significativo para a região contribuíram para esse incremento.

GRÁFICO 12

Taxas brutas de nupcialidade, natalidade e mortalidade da população livre Campinas - 1774-1822

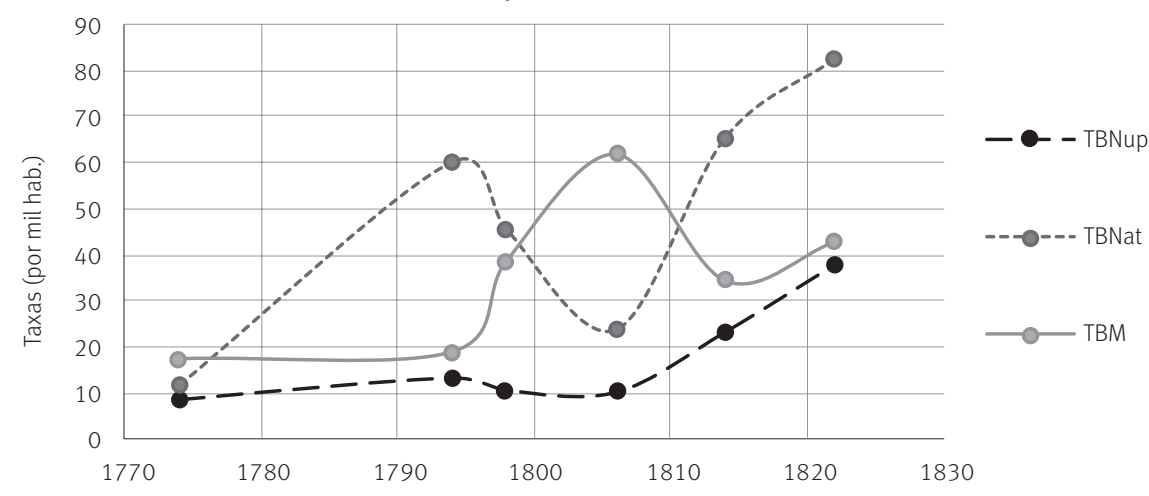

Fonte: Mapa Geral dos Habitantes de Campinas (Fundo Peter Eisenberg - Arquivo Edgard Leuenroth - Unicamp).

Por sua vez, ao considerar a população cativa (Gráfico 13), apesar da existência de um aumento importante dos nascimentos entre 1798 e 1822, as taxas de mortalidade, também elevadas, contribuíram para impedir um incremento natural positivo. Mas, a despeito disso, deve-se considerar a importância do processo migratório forçado de africanos, que, sobretudo nos anos 1820, fez crescer a população cativa em Campinas, como pudemos depreender da pirâmide etária apresentada no Gráfico 8. 
GRÁFICO 13

Taxas brutas de nupcialidade, natalidade e mortalidade da população cativa

Campinas - 1774-1822

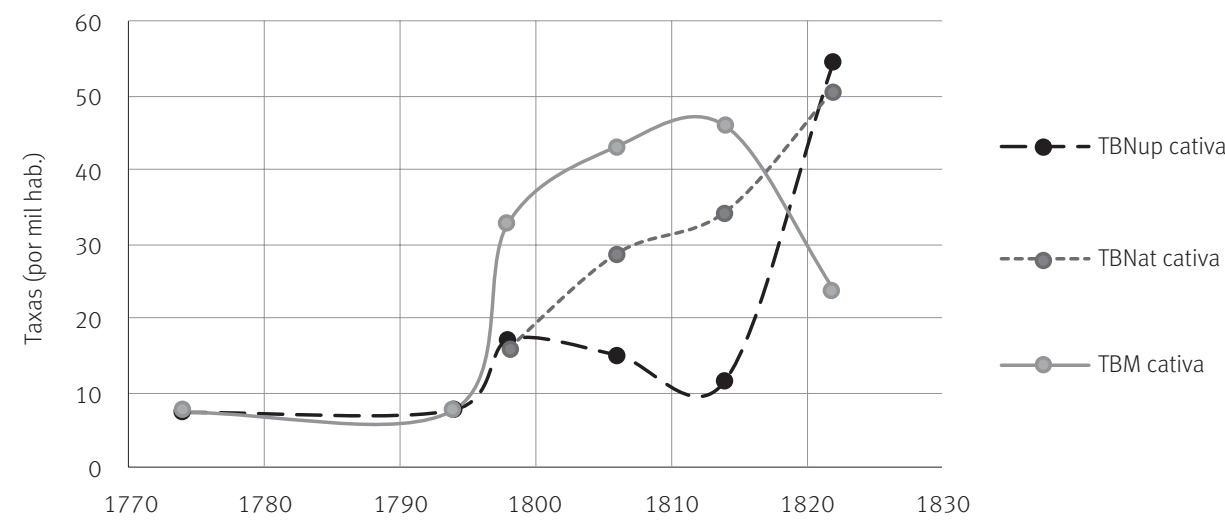

Fonte: Mapa Geral dos Habitantes de Campinas (Fundo Peter Eisenberg - Arquivo Edgard Leuenroth - Unicamp).

\section{Considerações finais}

Diante de mudanças econômicas e políticas que ocorreram a partir de meados do século XVII, o Império luso procurou dinamizar as regiões da América portuguesa que eram mais vulneráveis, promovendo a reestruturação da capitania de São Paulo e, como consequência, uma sucessão de atos que culminaram com o incentivo ao povoamento da terra de forma a explorá-la economicamente. Para isso, várias foram as vilas fundadas nesse momento, assim como fortificações foram construídas, como a do Iguatemy.

Campinas foi um exemplo de povoado que, ao sabor dos caminhos trilhados pelos bandeirantes, se tornou um pouso necessário para a jornada em direção ao sertão. Nesse processo, as terras férteis da região passaram a ser cultivadas, inicialmente, com produtos voltados ao comércio interno e consumo próprio. Porém, dada a conjuntura revolucionária francesa, que forçou o aumento dos preços internacionais do açúcar produzido no Caribe, São Paulo passou a ingressar nesse mercado, sendo que muitos habitantes de Campinas se beneficiaram desse processo, como demonstrou Valter Martins ao sugerir que não somente os senhores de engenho enriqueceram, mas também os pequenos agricultores livres.

Assim, as terras campineiras tornaram-se atrativas para muitas pessoas de condição social livre, algumas muito ricas, que implantaram engenhos e os colocaram sob os cuidados de administradores. Outras eram agricultores que faziam uso de poucos escravos e eram auxiliados pelos familiares, sendo que durante esse período muitos vieram a granjear bons resultados em suas lides agrícolas, enquanto outros migraram para lugares que chamavam a atenção dos colonizadores, como demonstrou Martins (1996).

0 fato é que a implantação de um número cada vez maior de engenhos provocou o ingresso de mais africanos para trabalharem sobre as condições do sistema escravista 
existente em Campinas, a exemplo de outras localidades estudadas por pesquisadores que partiram do referencial teórico da demografia histórica (COSTA, 1979; MOTTA, 1999; CUNHA, 2009). Assim, o objetivo deste artigo foi expressar as condições de implantação desse sistema desde os seus primeiros passos, à luz dos Mapas Gerais de Habitantes, e, sobretudo, extrair deles indicadores demográficos para melhor entender a dinâmica desse processo colonizador. Processo já identificado há um bom tempo por Maria Luiza Marcílio (2000) que, em sua análise, constatou a presença do escravo africano no meio do século XVIII em um quinto da população regional. Portanto, ao estudar Campinas, uma vila colonial que se estabeleceu no alvorecer da independência do Brasil, foi possível reforçar essa tese de Marcílio e perceber que, nesta vila colonial, a presença africana tornou-se ainda mais intensa, quase dividindo ao meio os espaços entre pretos e brancos.

\section{Referências}

ABREU, J. L. N. A Colônia enferma e a saúde dos povos: a medicina das 'luzes' e as informações sobre as enfermidades na América portuguesa. História, Ciências, Saúde - Manguinhos, Rio de Janeiro, v. 14, n. 3, p. 761-778, jul./set. 2007.

AISSAR, A. da G. Natalidade e mortalidade em Franca: estudo de demografia histórica (1800-1850). Tese (Doutorado) - Faculdade de Filosofia, Letras e Ciências Humanas (FFLCH), Universidade de São Paulo (USP), São Paulo, 1980.

ALINCOURT, L. D'. Memória sobre a viagem do porto de Santos à cidade de Cuiabá. São Paulo: Livraria Martins Editora, 1976.

BACELLAR, C. de A. P. As famílias de povoadores em áreas de fronteiras na capitania de São Paulo na segunda metade do século XVIII. In: VII CONGRESO DE LA ASOCIACIÓN LATINOAMERICANA DE POBLACIÓN. Anales... Foz do Iguaçu: Alap, 2016.

Os senhores da terra: família e sistema sucessório entre os senhores de engenho do oeste paulista, 1765-1855. Campinas: Centro de Memória Unicamp (CMU), 1997.

BELLOTTO, H. L. Autoridade e conflito no Brasil colonial: o governo do Morgado de Mateus em São Paulo (1765-1775). São Paulo: Secretaria Estadual da Cultura, 1979.

CABALLERO, E. M. C. A população de Montevidéu. Sua demografia histórica urbana: 1726-1852. Tese (Doutorado) - Faculdade de Filosofia, Letras e Ciências Humanas (FFLCH), Universidade de São Paulo (USP), São Paulo, 1987.

COSTA, I. N. da. Vila Rica: população (1719-1826). São Paulo: Instituto de Pesquisas Econômicas (IPE) da Universidade de São Paulo (USP), 1979 (Coleção Ensaios Econômicos, 1).

CUNHA, M. F. da. Demografia e família escrava. Franca-SP, século XIX. Tese (Doutorado) - Instituto de Filosofia e Ciências Humanas (IFCH), Universidade Estadual de Campinas (Unicamp), 2009.

DEAN, W. Rio Claro: um sistema brasileiro de grande lavoura, 1820-1920. Rio de Janeiro: Paz e Terra, 1977.

DOCUMENTOS Interessantes para a História e Costumes de São Paulo. São Paulo: Typ. Paulista, 1896.

EISENBERG, P. Homens esquecidos: escravos e trabalhadores livres no Brasil: séculos XVIII e XIX. Campinas: Universidade Estadual de Campinas (Unicamp), 1989. 
FERNANDES, M. de C. Imigração e ocupação em Campinas no final do século XIX ao início do século XX. Dissertação (Mestrado) - IFCH, Universidade Estadual de Campinas (Unicamp), Campinas, 2016.

HENRY, L. Temas de pesquisa, fontes e métodos da demografia histórica do Brasil. Revista de História (USP), São Paulo, n. 105, p. 63-79, jan./mar. 1976.

KUBO, E. M. Aspectos demográficos de Curitiba, 1801-1850. Dissertação (Mestrado) Universidade Federal do Paraná (UFPR), Curitiba, 1974.

LEMOS BRITO, J. G. de. Pontos de partida para a história econômica do Brasil. 3. ed. São Paulo: Editora Nacional; [Brasília]: INL, 1980 (Brasiliana; v. 155).

LEONZO, N. As companhias de ordenanças na capitania de São Paulo - das origens ao governo do Morgado de Matheus. São Paulo: Edição do Fundo de Pesquisa do Museu Paulista da USP, 1977 (Coleção Museu Paulista, série de História, v. 6).

LISTAS Nominativas de Habitantes. Fundo Peter Eisenberg - Arquivo Edgard Leuenroth - Unicamp. LIVRO Tombo da Paróquia de Nossa Senhora da Conceição de Campinas, volume 1. Arquivo da Cúria Metropolitana de Campinas.

LUNA, F. V. São Paulo: população, atividades e posse de escravos em vinte e cinco localidades (1777-1829). Estudos Econômicos, São Paulo, v. 28, n. 1, p. 99-169, jan./mar. 1998.

LUNA, F. V.; KLEIN, H. S. Evolução da sociedade e economia escravista de São Paulo, de 1750 a 1850. São Paulo: Edusp, 2005.

MAPA Geral dos Habitantes de Campinas. Fundo Peter Eisenberg - Arquivo Edgard Leuenroth - Unicamp.

MARCÍlIO, M. L. A cidade de São Paulo: povoamento e população, 1750-1850. São Paulo: Livraria Pioneira Editora; Editora da USP, 1974.

Caiçara: terra e população - estudo de demografia histórica e da história social de Ubatuba. São Paulo: Paulinas; Cedhal, 1986.

Edusp, 2000.

Crescimento demográfico e evolução agrária paulista: 1700-1836. São Paulo: Hucitec/

MARTINS, V. Nem senhores, nem escravos. Campinas: Centro de Memória Unicamp (CMU), 1996.

MOTTA, J. F. Corpos escravos, vontades livres: posse de cativos e família escrava em Bananal (1801 - 1829). São Paulo: Fapesp; Annablume, 1999.

NOZOE, N. Sesmarias e posse de terra rural no Entre Rios de Nossa Senhora da Conceição das Campinas do Matto Grosso. In: RIBEIRO, S. B. (Coord.). Sesmarias, engenhos e fazendas: Arraial dos Souzas, Joaquim Egydio, Jaguary (1792-1930). Campinas: Direção Cultura, v. 2, 2016. p. 10-55.

NOZOE, N.; COSTA, I. Achegas para a qualificação das Listas Nominativas. Estudos Econômicos, São Paulo, v. 21, n. 2, p. 271-284, maio/ago. 1991.

Sobre a questão das idades em alguns documentos dos séculos XVIII e XIX. Revista

Instituto Estudos Brasileiros, São Paulo, v. 34, p.175-182, 1992.

PETRONE, M. T. S. A lavoura canavieira em São Paulo. São Paulo: Difel, 1968.

PIROLA, R. F. A conspiração escrava de Campinas, 1832: rebelião, etnicidade e família. Dissertação (Mestrado) - Instituto de Filosofia e Ciência Humanas (IFCH), Universidade Estadual de Campinas (Unicamp), Campinas, 2005. 
REGISTROS paroquiais de batizados, casamentos e óbitos de livres e escravos de Campinas. Arquivo da Cúria Metropolitana de Campinas.

SLENES, R. W. A formação da família escrava nas regiões de grande lavoura do Sudeste: Campinas, um caso paradigmático no século XIX. População e Família, São Paulo, v. 1, n. 1, p. 9-82, jan./ jun. 1998.

. Na senzala, uma flor: esperança e recordações na formação da família escrava, Brasil Sudeste, século XIX. Rio de Janeiro: Nova Fronteira, 1999.

TEIXEIRA, P. E. O outro lado da família brasileira: mulheres chefes de família (1765-1850). Campinas: Unicamp, 2004.

A formação das famílias livres: Campinas, 1774-1850. São Paulo: Editora Unesp, 2011.

WELTI, C. Demografia. México: Prolap, 1997.

\section{Sobre 0 autor}

Paulo Eduardo Teixeira é doutor em História pela Universidade de São Paulo (USP). Professor do Programa de Pós-graduação em Ciências Sociais e da graduação da Universidade Estadual Paulista "Júlio de Mesquita Filho" (Unesp), campus de Marília.

\section{Endereço para correspondência}

Unesp - Universidade Estadual Paulista "Júlio de Mesquita Filho"

Departamento de Ciências Políticas e Econômicas (DCPE)

Av. Hygino Muzzi Filho, 737 - Bairro Mirante

17525-900 - Marília-SP, Brasil

\section{Abstract}

Campinas, a colonial village (1774-1822)

The development of agriculture in São Paulo, Brazil, presented a significant expansion during the late eighteenth and early nineteenth centuries, which is the focus of this paper. The purpose is to understand the dynamics and movements of these populations of a region of plantations (slaveholding properties). The sources for this discussion are derived from the General Map of Inhabitants existing for the period 1798-1822 in Campinas, with added data from the Nominative Lists of inhabitants and Parish Registers. Despite evident data limitation, there was a strong demographic increase, especially in captive population.

Keywords: Slavery, mortality. Marriage rate. Birth rate. 18th century. Settlement.

\section{Resumen}

Campinas, una villa colonial (1774-1822)

La agricultura paulista tuvo una expansión significativa durante los últimos años del siglo XVIII y los comienzos del XIX. En tanto región de grandes propiedades esclavistas, Campinas se estudia por su gran riqueza documental, de modo que este artículo fue pautado principalmente por el 
Mapa General de Habitantes del período 1798-1822, ampliado con información proveniente de las listas nominativas de habitantes y de los registros parroquiales. Finalmente, se verificó un crecimiento demográfico de gran intensidad, sobre todo en lo que refiere a la población esclava.

Palabras clave: Esclavitud. Mortalidad. Nupcialidad. Natalidad. Siglo XVIII. Colonización.

Recebido para publicação em 10/02/2017 Aceito para publicação em 09/10/2017 
